\title{
Paracardiac mass in echocardiography: a spontaneous giant pseudoaneurysm of the right coronary artery
}

\section{Introduction}

True and false (pseudo) aneurysms of the coronary arteries are very rare conditions. Pseudo-aneyrysm can be defined as a large, thin wall, narrowed neck dilatation of the coronary arteries not including all the layers of the vessel wall and communicating with there alarteri allumen. It is mostly associated with trauma, infections and catheter-induced dissection of the coronary arteries. Mean whiles pontaneous pseudoanuerysm of the coronary arteries are associated with spontaneous dissection. True and false aneurysm scan present as a variousclinicalresultssuch as sudden death, ischemiaor can be totally asymptomatic. ${ }^{1}$ IVUS or pathological examination is used to distinguish these conditions. ${ }^{2}$ Here in we report a case with a spontaneous pseudoaneurysm of the right coronary artery presented with chest pain, pericardial effusion and paracardiacmass.

\section{Case presentation}

27years old male patient admitted to our outpatient clinic with progressive, pleuritic chestpain unrelated to exertion for a month with no significant medical history. The patient was diagnosed with acute pericarditis at an center and receiving ibuprofen and colchium treatment for three weeks. There was no pathological finding on cardiacaus cultation, blood pressure was $110 / 80 \mathrm{mmHg}$, heart rate was $110 \mathrm{bpm}$. Electrocardiography showed sinustachicardia and minimal ST segment elevation in all leads. There was a slight cardiomegaly in chest X-ray (Figure 1). Cardiac markers and inflammatory marker were elevated; troponin-I 1112ng/L (0-100), CK748 U/L (0-190), CK-MB 95 U/L(3-25), ESR 65, CRP 75 was detected. Transthorasic echocardiography revealed a $45 \times 60 \mathrm{~mm}$ of cavitary mass compressing the right atrial free wall along with pericardial effusion (Figure 2); which was the only location of pericardial effusion in his previous examination a month ago. The patient was admitted to

\author{
Volume 7 Issue I - 2017
}

\author{
Burak Sezenoz,' Gökhan Gökalp, ${ }^{2}$ Ozden \\ Seckin, ${ }^{2}$ Özge Çakmak Karaaslan, ${ }^{2}$ Mustafa \\ HakanZor, ${ }^{3}$ Ayșe Dursun, ${ }^{4}$ Sedat Turkoglu ${ }^{2}$ \\ Atiye Cengel ${ }^{2}$ \\ 'Department of Cardiology, Gazi Mustafa Kemal State Hospital, \\ Turkey \\ ${ }^{2}$ Department of Cardiology, Gazi University School of Medicine, \\ Turkey \\ ${ }^{3}$ Department of Cardiovascular Surgery, University School of \\ Medicine, Turkey \\ ${ }^{4}$ Department of Pathology, Gazi University School of Medicine, \\ Turkey
}

Correspondence: Burak Sezenoz, Department of Cardiology, Gazi Mustafa Kemal State Hospital,Turkey, Tel +9053205 I7577, Fax+903 I22 I26666/6209, Email drburaksezenoz@gmail.com

Received: July 13, 2017 | Published: July 21, 2017

CCU. An aneursym 100x70x60mm in diameter, originating from right coronary artery extending to right atriallateral wall border and compressing externally, which contains thrombus material in its cavity was detected in cardiac computed tomography (CT) (Figure 3 ). Coronary angiography revealed a giant aneurysm communicated with RCA (Figure 4) without any abnormalty on left coronary arteries. The patient was given to emergency surgery because of the risk of pericardial tamponade. Aneurysmectomy was done and the remained cavity was closed primarily. Pathological examination was reported as polymorpho nuclear leukocyte and mononuclear inflammatory cell infiltration without elastic fibers and a pseudoaneursym of the coronary artery. The patient was discharged without any complication.

\footnotetext{
Figure I Cardiomegaly in chest X-Ray.
}

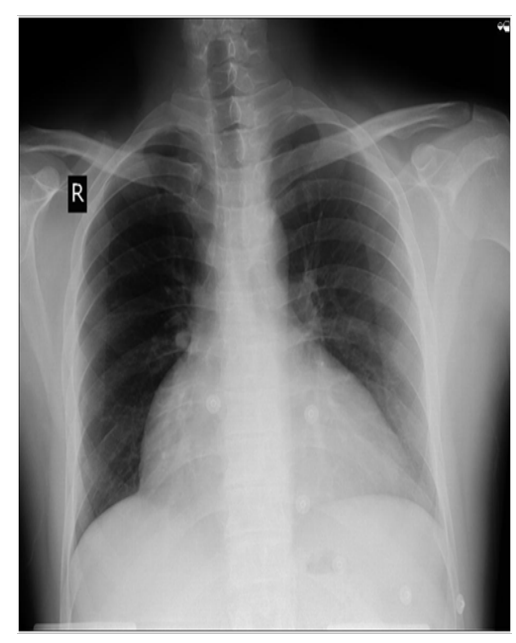




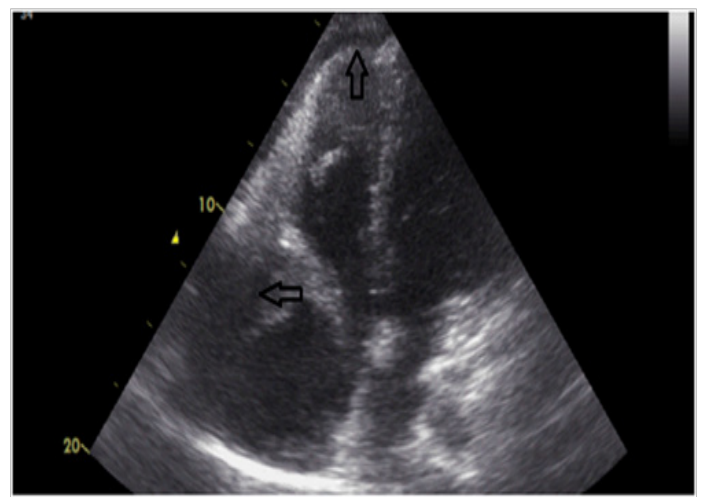

Figure $\mathbf{2}$ The cavitary mass compressing right atrium and the pericardial effusion.

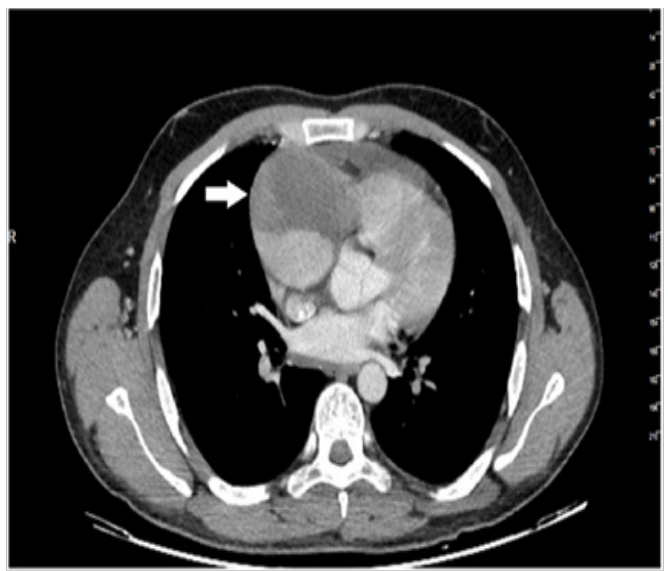

Figure 3 Right coronary artery aneurysm and the thrombus material extending to the right atrial lateral wall. (White arrow).

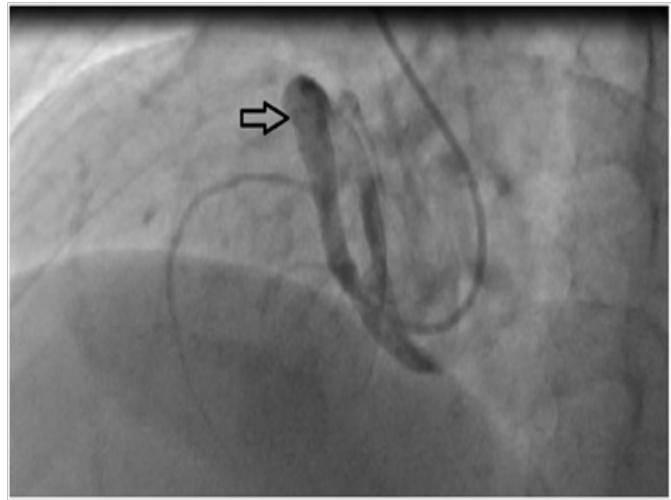

Figure 4 Giant right coronary artery aneurysm in coronary angiography (Black arrow).

\section{Discussion}

Here in we present a case spontaneous right coronary pseudoaneursym in a patient successfully managed with surgery. These patients can present as an acute cardiovascular event as well as can remain asymptomatic throughout the course. Our patient was suffering from ongoing chestpain for a month and also he was recieving anti inflamatory drugs for acute pericarditis. Elevated inflammatory and cardiacmarkers was the key point of the diagnosis. Coronary artery dissection can cause systemic inflammatory response reaction (SIRS) which help us to explain elevated CRP and ESR levels. Pericardial effusion can be secondary to reactive pericarditis and also may be the cause of the elevation of acute phase reactants but such an elevation in inflamatory markers after reactive pericarditis is not usual.

Our patient has no significant medical history and any factor that can cause true or false aneurysm such as atherosclerosis, Behcet's disease, Kawasaki disease, vasculitis, trauma or percutaneous coronary intervention. Sudden onset chest pain and a pseudoaneurysm formation without any precipitating factor helped us to diagnose spontaneous coronary artery dissection.

The giant aneursyms, which are diameter of $>20 \mathrm{~mm}$, more likely seen as a true aneurysm. ${ }^{3}$ IVUS could help us to distinguish these conditions; unfortunately we did not have the chance to perform; but since coronary angiography has no adequte visualisation of the artery, IVUS might be in efficent in this patient. Aneursyms must consist of all the layers vessel wall also the integrity must be maintained. ${ }^{4}$ In this patient the discrimination of the pseudoaneurysm with the true aneursym was made by histopathological assesment after surgery which revealed a pseudoaneurysm originated from right coronary artery restricted by epicardium without any relation with pericardium. Histopathological examination showed us disruption of the integrity of the vessel without the adventitia layer which lead us to pseudoaneursym as a result of spontaneus dissection of the coronary artery. There are few similar cases in the literature with giant coronary pseudoaneurysm where the final diagnosis was made by histopathology after surgery. Coronary CT scan can also be beneficial in decision making even in pregnant patients. ${ }^{5,6}$ The treatment of these patients must be tailored according to their presentation. Since coronary pseudoanerysms are quite rare, there is no evidence-based recommendation whether to treat medically or to perform surgery or percutaneous coronary intervention. Surgical treatment is mostly recommended in left main coronary or multivessel coronary arteries and giant aneurysms exceeding $30 \mathrm{~mm}$ in diameter. ${ }^{7}$ Surgery can be both therapeutic and diagnostic as in our patient. Since our patient has a risk of pericardial tamponade we performed a surgical intervention among all treatment possibilities.

In conclusion; spontaneous pseudoaneursyms are uncommon events. Diagnosis can be challenging as well as its treatment. Therapeutic intervention should be individualized and the surgery must be kept in mind in patients with a giant aneurysm and at the risk of pericardial tamponade.

\section{Acknowledgements}

None.

\section{Conflicts of interest}

The authors state that they have no conflict of interests.

\section{References}

1. Aqel RA, Zoghbi GJ, Iskandrian A. Spontaneous coronary artery dissection, aneurysms, and pseudoaneurysms: a review. Echocardiography. 2004;21(2):175-182.

2. Maehara A, Mintz GS, Castagna MT, et al. Intravascular ultrasound assesment of spontaneous coronary artery dissection. Am J Cardiol. 2002;89(4):466-468.

3. Jha NK, Ouda HZ, Khan JA, et al. Giant right coronary artery aneurysm casereport and literature review. J Cardiothorac Surg. 2009;4:18.

4. Syed M, Lesch M. Coronary artery aneurysm:a review. Prog Cardiovasc Dis. 1997;40(1):77-84. 
5. Wang YC, Hsu RB, Huang CH. Spontaneous giant right coronary artery pseudo aneurysm. J Thorac Cardiovasc Surg. 2014;148(1):349-350.

6. Omar HR, Mangar D, Camporesi EM. A paracardiac mass on chest $\mathrm{X}$-ray dueto giant LAD pseudoaneurysm. Ther Adv Cardiovasc Dis. 2014;8(2):70-71.
7. Aliyary S, Mariani MA, Verhorst PM, et al. Staged therapeutic approach in spontaneous coronary dissection. Ann Thorac Surg. 2007;83(5):18791881. 